\title{
Computer Modeling of Antibiotic Fermentation with On-Line Product Removal
}

\author{
Kevin H. Dykstra, Xiang-Ming Li, and H. Y. Wang \\ Department of Chemical Engineering, The University of Michigan, \\ Ann Arbor, Michigan 48109
}

Accepted for publication August 6, 1987

\begin{abstract}
The fermentation of Streptomyces griseus for the production of cycloheximide is similar to other antibiotic fermentations in that product synthesis is subject to feedback regulation and the desired product is degraded in the fermentation broth. The productivity of this fermentation can thus be dramatically increased by removing the antibiotic from the whole broth as it is produced. One means for effecting this on-line product removal is to contact the whole fermentation broth with neutral polymeric resin immobilized in hydrogel beads. The antibiotic adsorbs to the immobilized resin via hydrophobic interactions. In this work, the adsorption of the antibiotic onto the immobilized resin was characterized. A biochemical model of the fermentation was then used to describe the time profiles of biomass, substrate, and antibiotic in a fermentation system in which whole broth is circulated from the fermentor through a continuously stirred extractor containing the adsorbent beads. Various operating conditions were examined to optimize the productivity of the fermentation.
\end{abstract}

\section{INTRODUCTION}

The fermentation of Streptomyces griseus for the production of cycloheximide is typical of many antibiotic fermentations. Significant cell growth occurs only in the early part of the fermentation, and product synthesis commences only after growth stops. In addition, the desired product is subject to degradation in the fermentation broth, and its synthesis is feedback regulated. 'Product synthesis halts after glucose is exhausted in the medium. In previous work with this system, ${ }^{2,3}$ it has been shown that addition of neutral polymeric resin, to which the antibiotic adsorbs via hydrophobic interaction, greatly enhances both the rate of production and the overall amount produced. A fermentorextractor system was designed by Payne ${ }^{4}$ in which the whole broth is circulated from the fermentor through an extractor vessel where it is contacted with immobilized resin and has been shown to be an efficient means of removing the antibiotic from the fermentation broth as it is produced. Computer modeling of the batch fermentation has suggested that feedback repression may be the mechanism for feedback regulation in this system. ${ }^{5}$
In this work, the biochemical model for the production of cycloheximide was combined with a mathematical model of the extraction process. This complete model of the fermentation system was then used as a tool to evaluate the effects of various operating conditions and to look for ways of maximizing the production of cycloheximide.

\section{THEORY}

\section{Biochemical Model}

The feedback repression model for the cycloheximide fermentation is discussed in detail elsewhere ${ }^{5}$ and thus will only be summarized here. In this model, the state variables include the concentrations of biomass, carbon substrate (glucose), cycloheximide, and an intracellular, rate limiting enzyme that controls the synthesis rate of cycloheximide.

Because the cell growth characteristics of this system are poorly characterized and difficult to determine, a simple logistic growth model, ${ }^{6}$ given by

$$
R_{X}=\mu_{\max }\left(1-\frac{X}{X_{\max }}\right) X
$$

was used to describe cell growth.

The desired product, cycloheximide, was taken to be subject to both synthesis and degradation while in the fermentation broth. Following an initial time lag due to an observed delay in the onset of antibiotic synthesis, the rate of product synthesis is proportional to the concentration of rate-limiting enzyme inside the cells:

$$
R_{P}=Q_{P 0} E X
$$

The degradation of cycloheximide has been shown ${ }^{4}$ to follow first-order kinetics with respect to the antibiotic concentration; thus,

$$
R_{\mathrm{DP}}=k_{\mathrm{DP}} P
$$

The rate-limiting enzyme was also taken to be subject to synthesis and degradation. However, its rate of synthesis is 
affected by the presence of cycloheximide via feedback repression of the gene coding for the protein:

$$
R_{E}=\frac{Q_{E 0}}{1+P / K_{r}}
$$

Proteolysis of the rate-limiting enzyme was taken as a first-order process:

$$
R_{\mathrm{DE}}=k_{\mathrm{DE}} E
$$

Finally, the utilization of glucose was taken to be due to cell growth, cycloheximide synthesis, and cell maintenance:

$$
-R_{\mathrm{S}}=\frac{1}{Y_{X / S}} R_{X}+\frac{1}{Y_{P / S}} R_{P}+m X
$$

\section{Adsorption Model}

The adsorber for this system consists of a well-stirred vessel containing neutral polymeric resin immobilized in hydrogel beads. The fermentation broth is circulated from the main fermentor vessel to the adsorber. In the adsorber model, the product removal rate was found by simulating the adsorption of cycloheximide in a single hydrogel bead.

A schematic diagram of the immobilized adsorbent bead is shown in Figure 1. In considering the hydrogel bead, it was assumed that the resin particles were infinitely crushed and uniformly distributed throughout the bead. The processes occurring within the bead include (1) mass transfer of cycloheximide from the bulk extractor liquid across a boundary layer, (2) diffusion through the hydrogel matrix, and (3) adsorption onto the resin particles. It was assumed that the kinetics of adsorption are rapid compared with the diffusion rate, so that the resin could be assumed to be at equilibrium with the local concentration in the bead. The adsorption of cycloheximide onto crushed resin was found to follow a Freundlich-type isotherm?

$$
P_{s}=k_{1} P_{r}^{k_{2}}
$$

The nonlinear, partial differential equation describing the diffusion and adsorption of the product into the bead is thus

$$
\frac{1}{r^{2}} \frac{\partial}{\partial_{r}}\left[r^{2} D_{\mathrm{eff}} \frac{\partial P_{r}}{\partial r}\right]=\left[\varepsilon+C_{r} k_{1} k_{2} P_{r}^{k_{2}-1}\right] \frac{\partial P_{r}}{\partial t}
$$

The boundary and initial conditions were as follows: (1) no flux across the center of the bead; (2) continuity of flux

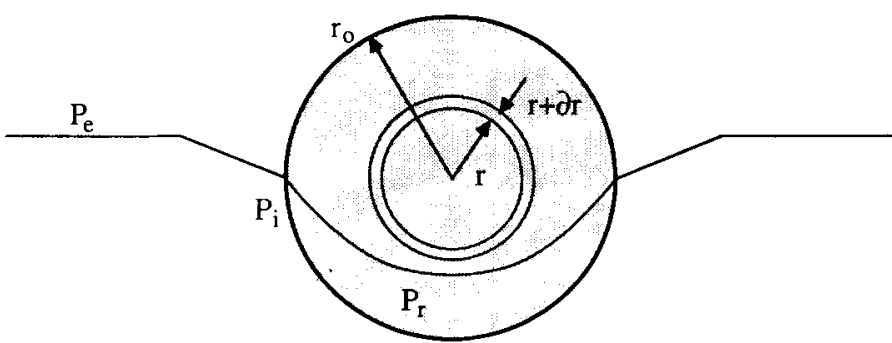

Figure 1. Schematic diagram of immobilized adsorbent bead. Adsorbent is Rohm and Haas XAD-4 neutral polymeric resin. Adsorbent assumed to be infinitely crushed and uniformly distributed throughout bead. across the bead-liquid interface, and (3) completely unloaded beads at time $t=0$ :

$$
\begin{array}{rlrl}
r=0: & & \frac{\partial P_{r}}{\partial r} & =0 \\
r & =r_{0}: & & \frac{\partial P_{r}}{\partial r}=\frac{k_{p}}{D_{\text {eff }}}\left(P_{a}-P_{i}\right) \\
t=0: & P_{r}=0
\end{array}
$$

The solution to this equation was approximated for a discrete time interval using a fully implicit finite-difference algorithm and an average surface flux calculated from the change in the net cycloheximide loading in the bead. From a knowledge of the total volume of beads in the extractor, $V_{b \text {, tot }}$, and the average bead size $v_{b}$, the volumetric rate of product removal from the extractor could be calculated:

$$
R_{\mathrm{ADS}}=\frac{\Delta \int_{0}^{r_{0}} 4 \pi r^{2}\left(\varepsilon P_{r}+C_{r} k_{1} P_{r}^{k_{2}}\right) d r}{\Delta t} \frac{V_{b, \text { tol }}}{v_{b} V_{a}}
$$

\section{Combination of Models for Fermentor and Adsorber}

A schematic diagram of the fermentor-adsorber system is shown in Figure 2. Both vessels are well stirred, and whole fermentation broth is circulated from the fermentor to the extractor where it is contacted with the immobilized resin beads. In the experimental system the fermentor holds roughly $10 \mathrm{~L}$ working volume and it agitated using a flatblade turbine. The adsorber contained $2 \mathrm{~L}$ working volume and was stirred with a marine propellor to avoid shear damage to the immobilized adsorbent beads. The nonlinear, differential mass balance equations describing the system are given in Table I. Each of the rates was calculated using the fermentation state at a particular time, and the solution to the system was approximated using a fourth-order Hammings variable-step-size predictor-corrector algorithm. ${ }^{8}$

\section{MODEL VERIFICATION}

The estimation of parameters for the feedback repression model has been previously discussed. ${ }^{5}$ This model must account for three distinct fermentation cases: (1) the normal batch fermentation with no product removal, (2) the case where enough glucose is present for complete feedback regulation to occur (no product removal), and (3) the fermentation where enough resin is added to the batch fermentation to essentially completely remove the antibiotic from the broth. Data for each of these three cases are shown in Figure 3. In the normal batch case, ${ }^{9}$ cells were cultivated in a 3-L fermentor and samples withdrawn at the indicated times. The maximum cycloheximide concentration corresponds to the exhaustion of glucose in the medium. In the supplemental glucose case, ${ }^{4}$ excess glucose was initially present in a shake flask fermentation $(50 \mathrm{~mL}$ in a 250 -mL flask; $100 \mathrm{~g} / \mathrm{L}$ glucose). Cycloheximide could thus accumulate to its maximum feedback regulated level. 


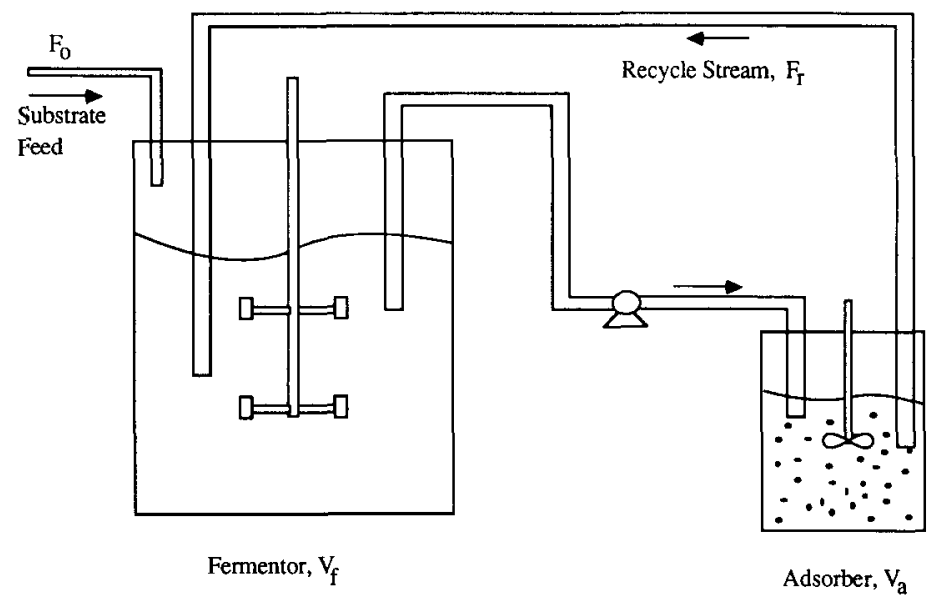

Figure 2. Schematic diagram of fermentor-adsorber system. Whole broth is circulated from fermentor through adsorber, where it is contacted with immobilized adsorbent beads.

For the fermentation with product removal, ${ }^{9}$ the cells were grown in the 3-L fermentor in the presence of 3.3\% XAD-4 neutral resin, which allowed essentially no cycloheximide to accumulate in the broth. It is easily seen that the total production is substantially higher than in either of the two previous cases. The curves in Figure 3 are the simulated cycloheximide concentration profiles for each of the three fermentations obtained using the feedback repression model.

In characterizing the adsorption kinetics, the first task was to define the physical characteristics of the adsorbent bead. The beads were prepared by first soaking $20 \mathrm{~g}$ crushed resin (Rohm and Haas, XAD $-4, D_{p}<0.15 \mathrm{~mm}$ ) in $95 \%$

Table I. Differential equations describing fermentor-adsorber system.

Fermentor balances:

$$
\begin{aligned}
& \frac{d X_{f}}{d t}=\frac{F_{R}}{V_{f}}\left(X_{a}-X_{f}\right)+R_{X_{f}}-\frac{F_{0}}{V_{f}} X_{f} \\
& \frac{d S_{f}}{d t}=\frac{F_{R}}{V_{f}}\left(S_{a}-S_{f}\right)+R_{S_{f}}+\frac{F_{0}}{V_{f}}\left(S_{0}-S_{f}\right) \\
& \frac{d P_{f}}{d t}=\frac{F_{R}}{V_{f}}\left(P_{a}-P_{f}\right)+R_{P_{f}}-R_{\mathrm{DP}_{f}}-\frac{F_{0}}{V_{f}} P_{f} \\
& \frac{d E_{f}}{d t}=\frac{F_{R}}{V_{f} X_{f}}\left(X_{a} E_{a}-X_{f} E_{a}\right)+R_{E_{f}}-R_{\mathrm{DE}_{f}}-\frac{F_{0}}{V_{f}} E_{f}-\frac{E_{f}}{X_{f}} \frac{d X_{f}}{d t} \\
& \frac{d V_{f}}{d t}=F_{0}
\end{aligned}
$$

Adsorber balances:

$$
\begin{aligned}
& \frac{d X_{a}}{d t}=\frac{F_{R}}{V_{a}}\left(X_{f}-X_{a}\right)+R_{X_{a}} \\
& \frac{d S_{a}}{d t}=\frac{F_{R}}{V_{a}}\left(S_{f}-S_{a}\right)+R_{S_{a}} \\
& \frac{d P_{a}}{d t}=\frac{F_{R}}{V_{a}}\left(P_{f}-P_{a}\right)+R_{P_{a}}-R_{\mathrm{DP}_{a}}-R_{\mathrm{ADs}} \\
& \frac{d E_{a}}{d t}=\frac{F_{R}}{X_{a} V_{a}}\left(X_{f} E_{f}-X_{a} E_{a}\right)+R_{E_{a}}-R_{\mathrm{DE}_{a}}-\frac{E_{a}}{X_{a}} \frac{d X_{a}}{d t}
\end{aligned}
$$

ethanol overnight. The resin was then thoroughly washed in distilled water and mixed with alginate solution to give a slurry containing $12.5 \%(\mathrm{w} / \mathrm{v})$ resin and $0.5 \%(\mathrm{w} / \mathrm{v})$ alginate. The slurry was added dropwise to a gently stirred $2 \% \mathrm{CaCl}_{2}$ solution and allowed to harden $8-10 \mathrm{~h}$. The volume of the beads was found by measuring the amount of water displaced by a given number of beads $\left(v_{b}=0.0395 \pm\right.$ $0.003 \mathrm{~mL} /$ bead at the $95 \%$ confidence level), and the porosity was found by weighing the amount of water lost upon drying $(\varepsilon=0.84 \pm 0.035)$.

The adsorption isotherm was measured at $25^{\circ} \mathrm{C}$ by measuring the amount of cycloheximide adsorbed from $50 \mathrm{~mL}$ solution with varying starting concentrations. Cycloheximide was measured using the photometric assay of Takeshita et al. ${ }^{10}$ The curve of resin loading vs. supernatant concentration, shown in Figure 4, conformed closely to a Freundlich isotherm:

$$
P_{s}=k_{1} P_{a}^{k_{2}}
$$

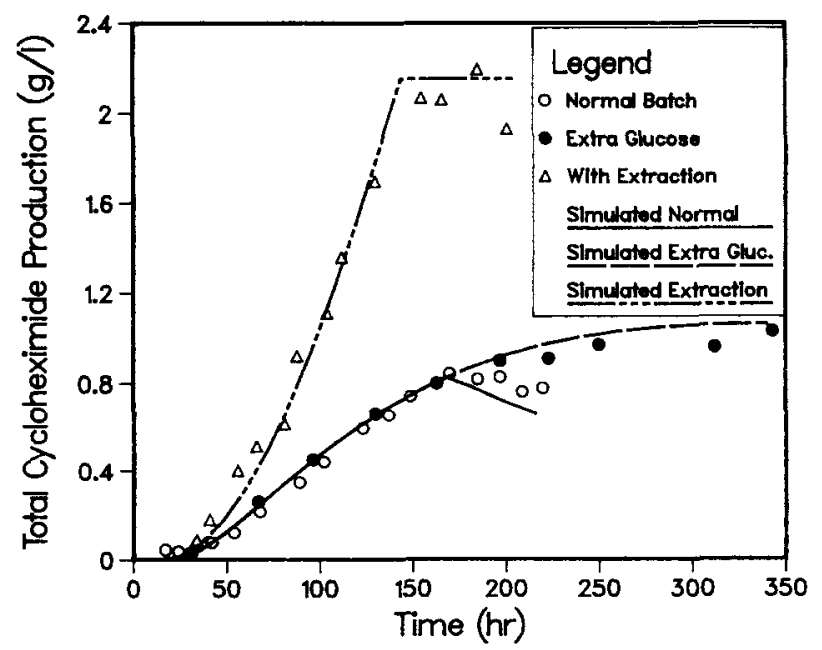

Figure 3. Experimental cycloheximide profiles for typical batch fermentations vs. simulated profiles using model with feedback repression. 


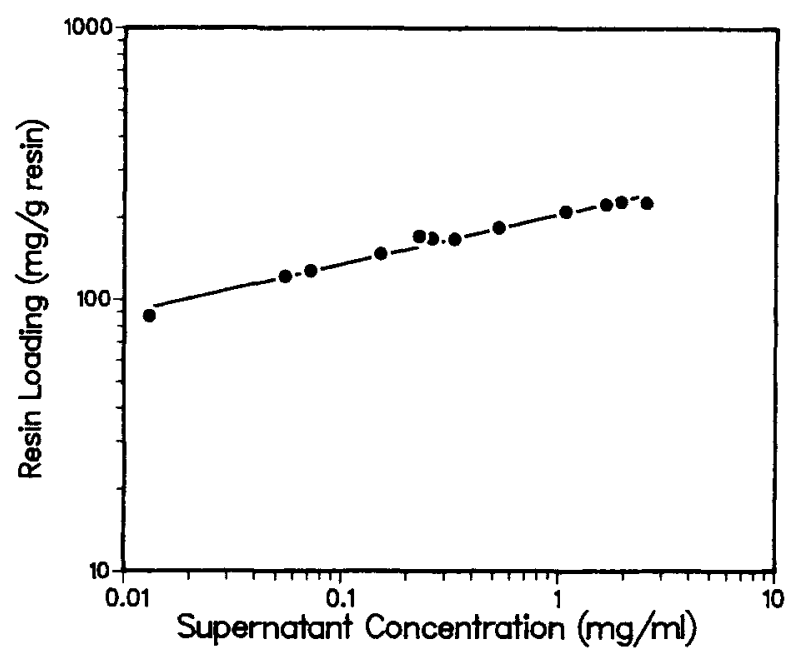

Figure 4. Adsorption isotherm for cycloheximide on crushed XAD-4 resin at $25^{\circ} \mathrm{C}$

Linear regression of the $\log -\log$ plot of $P_{s}$ vs. $P_{a}$ gave adsorption parameters $k_{1}=206 \mathrm{mg} / \mathrm{g}$ resin and $k_{2}=0.182$.

In order to estimate the mass transfer coefficient $k_{p}$, the initial rate of product removal was observed in batch adsorption experiments in the adsorber vessel. Using the data shown in Figure 5 from two different kinetic adsorption studies and assuming the initial interfacial cycloheximide concentration $P_{i}$ to be zero, the mass transfer equation

$$
\frac{d P_{a}}{d t}=k_{p} a\left(P_{a}-P_{i}\right)
$$

was solved for $k_{p}$. This procedure yielded an average value of $k_{p}=4.67 \pm 0.16 \times 10^{-4} \mathrm{~cm} / \mathrm{s}$ in water at $25^{\circ} \mathrm{C}$ with an agitation rate in the adsorber of roughly $120 \mathrm{rpm}$.

An effective diffusion coefficient in the hydrogel was fit using the preceding calculated parameter values and data from a batch adsorption experiment. Figure 6 shows the experimental and simulated concentration profiles using a diffusion coefficient $D_{\text {eff }}=7.0 \times 10^{-6} \mathrm{~cm}^{2} / \mathrm{s}$. This value compares well with the diffusion coefficient for cycloheximide found in studies of immobilized, uncrushed resin ${ }^{1}$ and for other molecules of similar size. ${ }^{12}$

Finally, Figure 7 shows the results of a batch adsorption run using the fermentor-extractor system and a cycloheximide-water solution. The fermentor was initially loaded with $10 \mathrm{~L}$ cycloheximide solution $(1.0 \mathrm{~g} / \mathrm{L})$, while the adsorber contained $0.33 \mathrm{~L}$ beads in $1.67 \mathrm{~L}$ distilled water. At time $t=0$ the circulating pump was turned on, and the cycloheximide concentration in both vessels was measured as a function of time. It can be seen that the computer model does a good job of predicting the concentration profiles in both the fermentor and the adsorber vessels.

\section{SIMULATION RESULTS}

In the next portion of this work, various operating conditions were evaluated using the complete model in order to determine the best way to run the fermentor-adsorber system. Here, the adsorber working volume was taken as

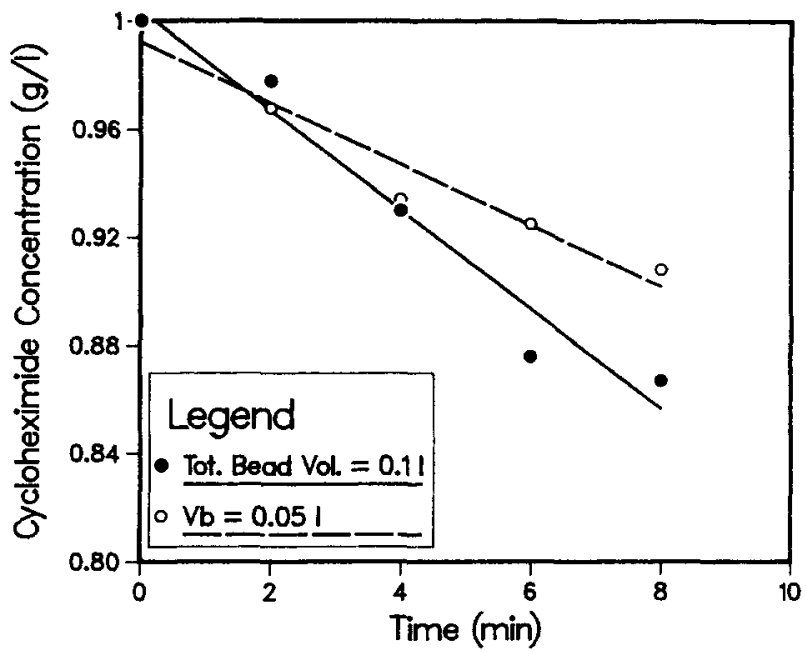

Figure 5. Initial rate experiments used to find mass transfer coefficient from adsorber bulk to bead interface.

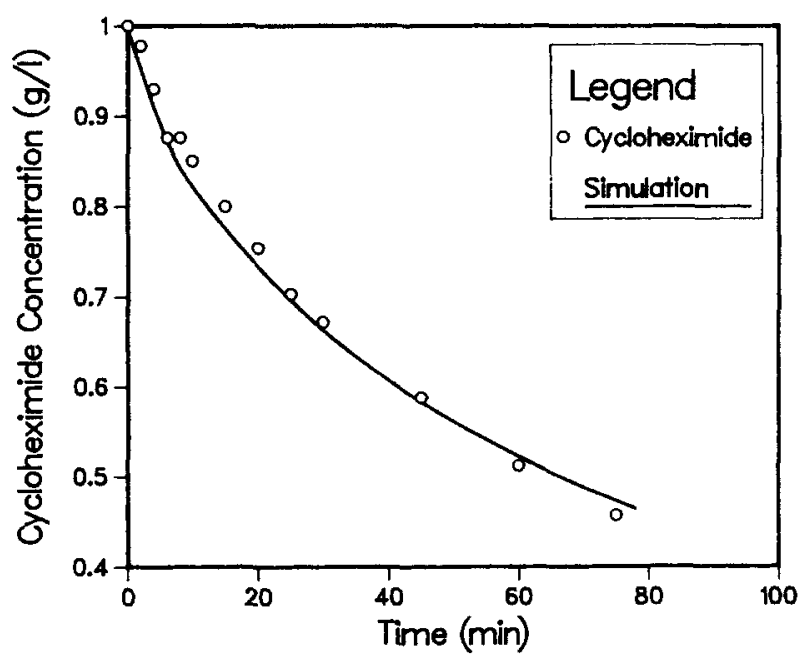

Figure 6. Batch adsorption time profile used to find effective diffusion coefficient of cycloheximide in immobilized adsorbent bead. Effective diffusion coefficient of $7.0 \times 10^{-6} \mathrm{~cm}^{2} / \mathrm{s}$ gave best fit with experimental data.

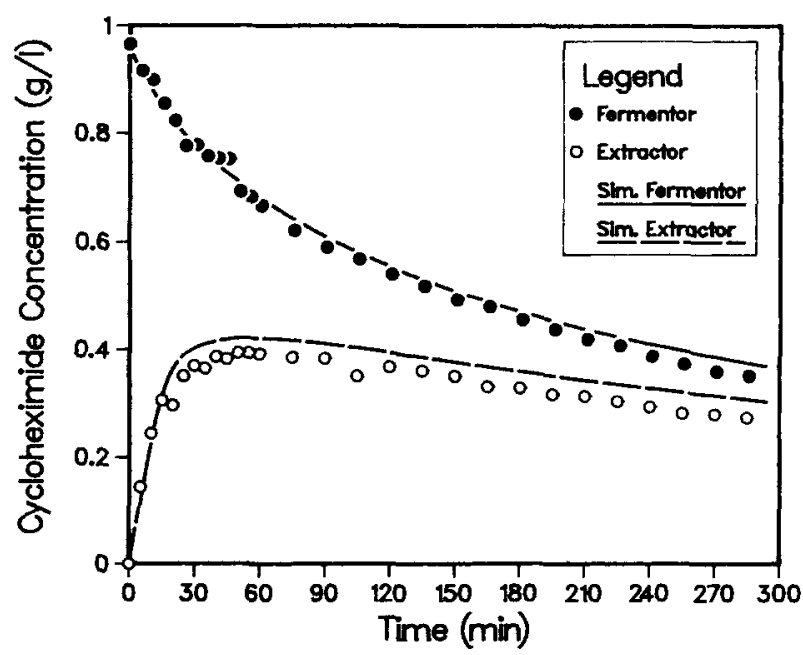

Figure 7. Adsorption experiment in fermentor-adsorber system vs. simulated profiles for fermentor and adsorber vessels. 
one-tenth the fermentor working volume, corresponding to the relative sizes of industrially used fermentor and inoculum vessels. Kinetic parameter values found in the preceding and in ref. 5 were used, and the batch mode of operation was examined exclusively. The objective function used to evaluate the system performance was the fermentor productivity, defined as

$$
J=\frac{P_{\mathrm{tol}}}{t_{\text {final }}}
$$

where $P_{\text {tot }}$ is the total antibiotic produced per fermentor volume and $t_{\text {final }}$ is the time required to reach the maximum total antibiotic production.

The first operating parameter to be evaluated was the recycle flow rate. It might be expected that the productivity of the fermentation should depend strongly on the recycle flow rate as low flow rates and should approach a maximum when the mean residence time in the adsorber $\left(V_{a} / F_{r}\right)$ is significantly longer than the time required to adsorb the product from the broth. From Figure 8 , it can be seen that this is indeed the case and that relatively low recycle rates $\left(F_{r}>0.2\right.$ fermentor volumes $\left./ \mathrm{h}, V_{a} / F_{r}>0.5\right)$ give completely adequate product removal.

The dependence of productivity on adsorption capacity was next examined. Again, it would be expected that the productivity should approach an asymptotic value when enough adsorbent is present so that there is essentially no cycloheximide in the broth. This was the situation used to gather the data for the "extracted" fermentation in Figure 3 , where the productivity was roughly $13 \mathrm{mg} / \mathrm{L} \mathrm{h}$. However, it should be pointed out here that there are some limitations to the amount of adsorbent resin that can be loaded into the bead and on how many beads can be placed in the extractor. Figure 9 shows the results for a simulation using beads that are $19 \%$ by weight resin. At this resin content, the immobilized beads have good mechanical strength; with higher resin content, they tend to disinte-

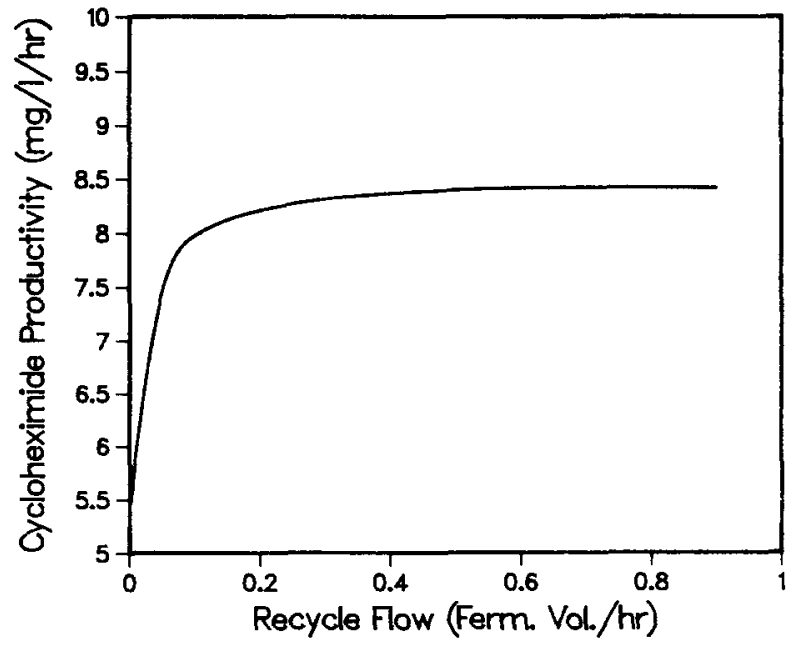

Figure 8. Dependence of fermentation productivity on recycle flow between fermentor and adsorber. grate due to shear forces in the adsorber. In addition, the total amount of beads in the adsorber is limited to less than $30 \%$ of the total adsorber volume due to mixing considerations. Thus, it is clearly seen from Figure 9 that the productivity is a strong function of the adsorbent capacity for the simulated fermentor-adsorber configuration.

Figures 10a and 10b show simulated time profiles of total cycloheximide production and the concentration of the rate-limiting enzyme in the fermentor for the normal batch fermentation and the fermentation with continuous product extraction. It is interesting to note that while the actual antibiotic concentration is low early in the production phase of the fermentation, the synthetic enzyme concentration is a substantial portion of its final value and goes through a maximum value. This type of behavior is experimentally observed in other antibiotic producing systems, for example, in the production of mycophenolic acid, ${ }^{13}$ puromycin, ${ }^{14}$ and tetracycline. ${ }^{15}$

The early appearance of the enzyme implies that product extraction is most important early in the fermentation. The effect of delaying extraction varying times after the initiation of antibiotic synthesis is shown in Figure 11a. It can be easily seen that the later the extraction process is begun, the lower the productivity of the fermentation. In contrast, Figure $11 \mathrm{~b}$ shows the effect of running the extractor for varying lengths of time, starting at the initiation of antibiotic synthesis. Again, it can be seen that the most important time for product extraction is early in the fermentation. The increase in fermentation productivity occurs in the first $70-80 \mathrm{~h}$ product extraction; there is little additional productivity to be gained after that.

\section{CONCLUSIONS}

In this work, the product adsorption process has been characterized for cycloheximide in an immobilized adsorbent bead. The biochemical model of the synthetic process was combined with the adsorption model to give a complete

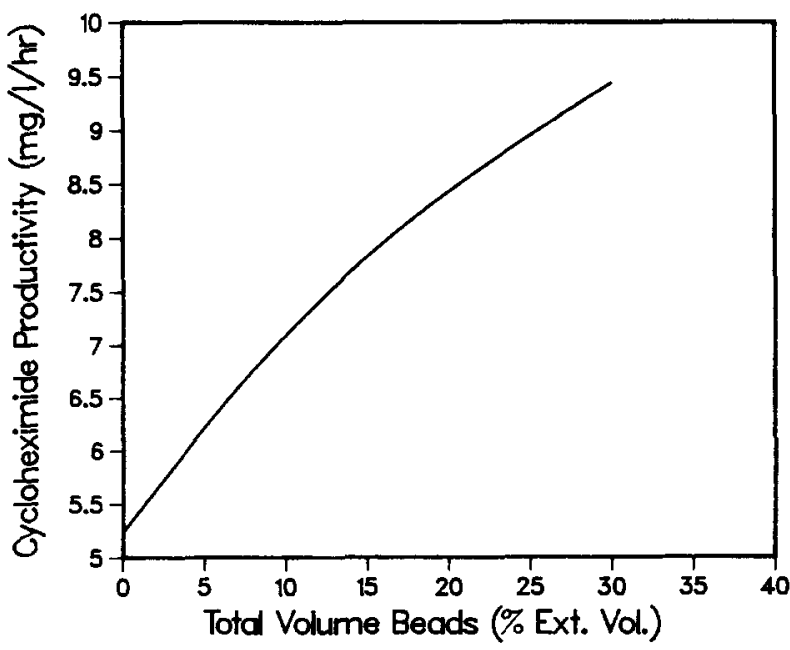

Figure 9. Dependence of productivity on amount of adsorbent in adsorber 


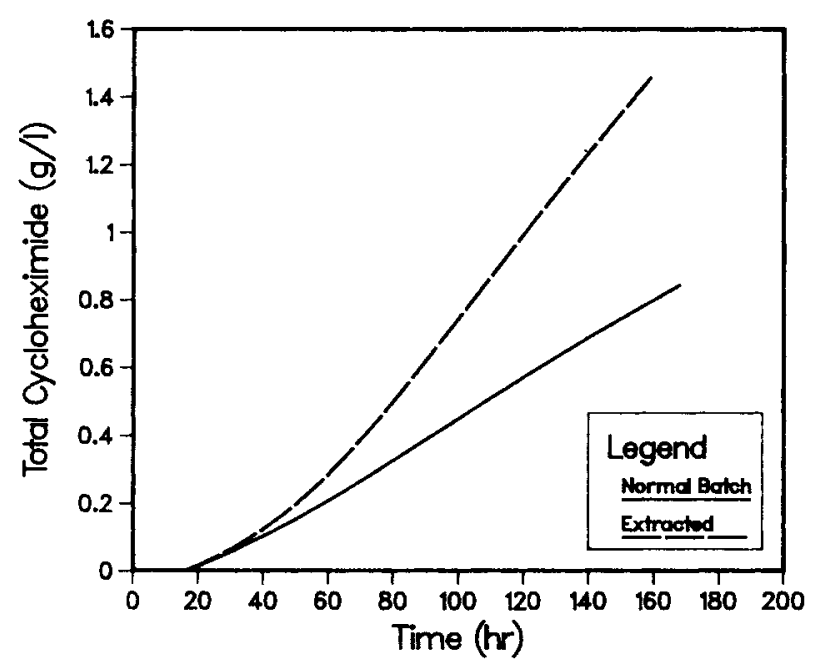

(a)

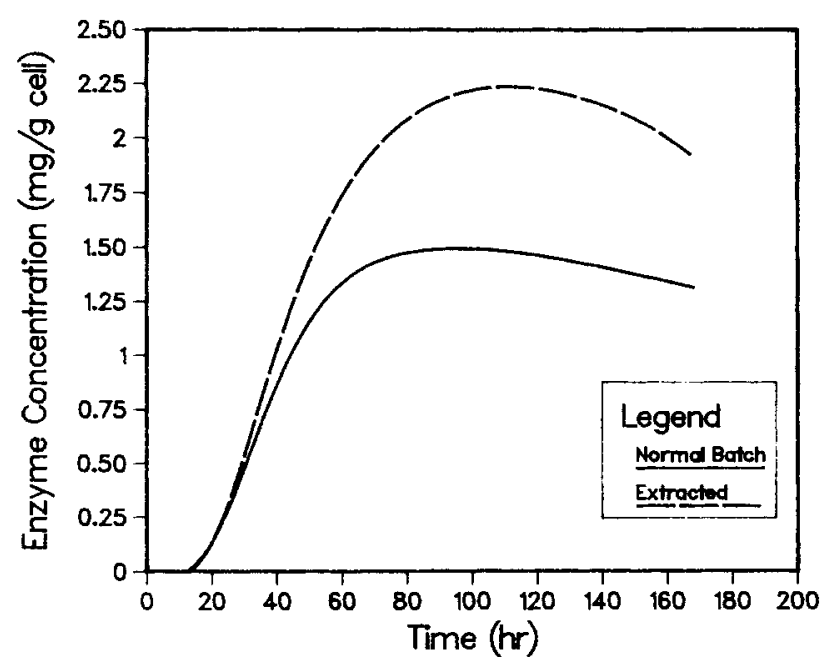

(b)

Figure 10. (a) Simulated total cycloheximide production profiles for normal batch fermentation and fermentation in fermentor-adsorber system. (b) Simulated concentration profiles for intracellular rate-limiting enzyme.

model of the fermentation process with on-line product removal. The complete model of the fermentor-adsorber system was then used to evaluate various methods of operation for the system. It was shown that a relatively low recycle flow rate is completely adequate for product removal and that within the limits of the adsorber vessel productivity of the fermentation is a strong function of the amount of adsorbent present. Finally, it was suggested that for a feedback repressed system the early part of the fermentation is most crucial for product removal. Product synthesis is limited by the intracellular enzyme concentration, and these enzymes are produced early in production phase.

\section{NOMENCLATURE}

State variables

$X$ biomass concentration $(\mathrm{g} \mathrm{DCW} / \mathrm{L})$

$S \quad$ glucose concentration $(\mathrm{g} / \mathrm{L})$

$P \quad$ cycloheximide concentration ( $\mathrm{g} \mathrm{CH} / \mathrm{L}$ )

$E$ intracellular enzyme concentration (g protein $/ \mathrm{g} \mathrm{DCW}$ )

$V \quad$ liquid volume (L)

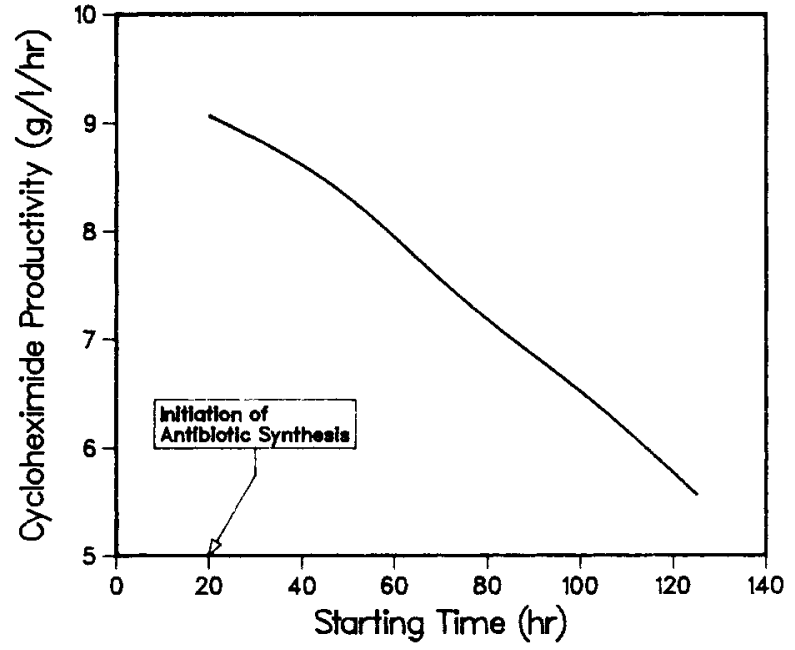

(a)

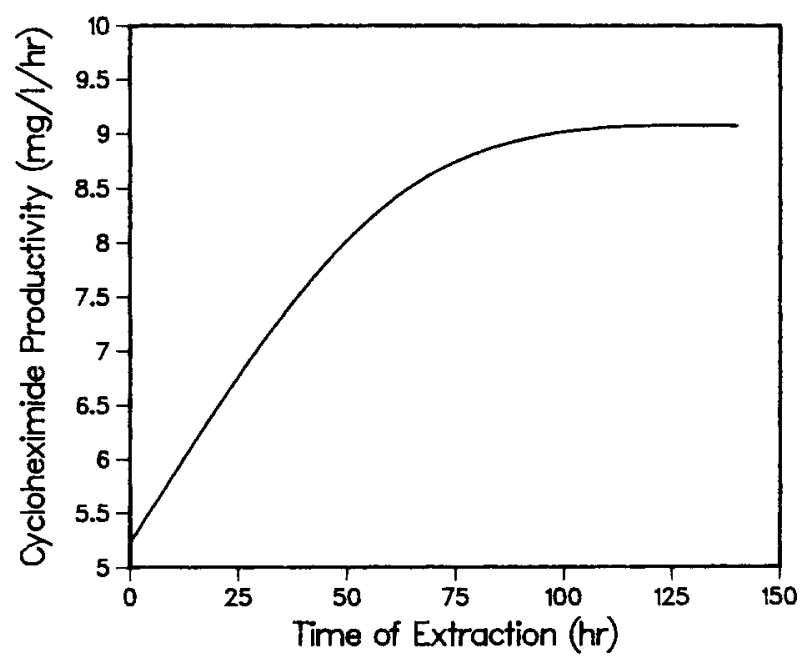

(b)

Figure 11. (a) Effect of delaying extraction on fermentation productivity. (b) Effect of duration of extraction following onset of antibiotic synthesis.

Rates

$R_{X} \quad$ cell growth ( $\left.\mathrm{g} \mathrm{DCW} / \mathrm{L} \mathrm{h}\right)$

$R_{S} \quad$ substrate utilization (g glucose/L h)

$R_{p} \quad$ antibiotic synthesis $(\mathrm{g} \mathrm{CH} / \mathrm{L} \mathrm{h})$

$R_{\mathrm{DP}} \quad$ product degradation $(\mathrm{g} \mathrm{CH} / \mathrm{L} \mathrm{h})$

$R_{E} \quad$ intracellular enzyme (g protein $/ \mathrm{g} \mathrm{DCW} \mathrm{h}$ )

$R_{\mathrm{DE}} \quad$ enzyme degradation rate (g protein $/ \mathrm{g} \mathrm{DCW} \mathrm{h)}$

$R_{\mathrm{ADS}}$ product removal by adsorption $(\mathrm{g} \mathrm{CH} / \mathrm{L} \mathrm{h})$

\section{Parameters}

$\mu_{\max }$ maximum specific growth rate $\left(\mathrm{h}^{-1}\right)$

$X_{\max }$ maximum attainable biomass concentration ( $\mathrm{g} \mathrm{DCW} / \mathrm{L}$ )

$Q_{P 0} \quad$ specific productivity of intracellular enzyme $(\mathrm{g} \mathrm{CH} / \mathrm{g}$ protein $\mathrm{h})$

$k_{\mathrm{DP}}$ degradation rate constant for cycloheximide $\left(\mathrm{h}^{-1}\right)$

$Q_{E 0} \quad$ maximum rate of intracellular enzyme synthesis (g protein/g DCW h)

$K_{r} \quad$ feedback repression constant $(\mathrm{g} \mathrm{CH} / \mathrm{L})$

$k_{\mathrm{DE}}$ degradation rate constant for intracellular enzyme $\left(\mathrm{h}^{-1}\right)$

$Y_{X / S} \quad$ yield of biomass on glucose ( $\mathrm{g} \mathrm{DCW} / \mathrm{g}$ glucose)

$Y_{P, S} \quad$ yield of cycloheximide on glucose ( $\mathrm{g} \mathrm{CH} / \mathrm{g}$ glucose)

$m$ basal metabolic substrate utilization (g glucose/g DCW h)

$C_{r} \quad$ resin content of hydrogel bead $(\mathrm{g} r e s i n / \mathrm{mL}$ bead)

$k_{1} \quad$ "capacity" of XAD-4 resin for cycloheximide $(\mathrm{mg} \mathrm{CH} / \mathrm{g}$ $\operatorname{resin}) /(\mathrm{g} \mathrm{CH} / \mathrm{L})^{k_{2}}$ 
$k_{2} \quad$ intensity of adsorption onto XAD-4 resin (dimensionless)

$D_{\text {eff }}$ effective diffusion coefficient in hydrogel $\left(\mathrm{cm}^{2} / \mathrm{s}\right)$

$\varepsilon \quad$ porosity of immobilized adsorbent beads (fraction voids)

$k_{p} \quad$ mass transfer coefficient between adsorber bulk and bead interface $(\mathrm{cm} / \mathrm{s})$

$F_{R} \quad$ recycle flow rate $(\mathrm{L} / \mathrm{h})$

$F_{0} \quad$ feed rate for substrate addition $(\mathrm{L} / \mathrm{h})$

$S_{0} \quad$ concentration of substrate in feed ( $\mathrm{g}$ glucose $/ \mathrm{L}$ )

Subscripts:

$f \quad$ fermentor

adsorber

adsorbent bead

liquid bead interface

\section{References}

1. L. A. Kominek, Antimicrob. Agents Chemotherap., 7, 856 (1975).

2. H. Y. Wang, Ann. NYAS, 413, 313 (1983).

3. H. Y. Wang and K. Sobnosky, ACS Symp., 271, 123 (1984).
4. G. F. Payne, Ph.D. Dissertation, University of Michigan, 1984.

5. K. H. Dykstra and H. Y. Wang, Ann. NYAS, 506, 511 (1987).

6. J. E. Bailey and D. F. Ollis, Biochemical Engineering Fundamentals, 1st ed. (McGraw-Hill, New York, 1977), p. 407.

7. A. W. Adamson, Physical Chemistry of Surfaces, 3rd ed. (Wiley, New York, 1960), p. 386.

8. A. Ralston, Mathematical Methods for Digital Computers (Wiley, New York, 1960), p. 95.

9. F. M. Robinson and H. Y. Wang, unpublished data, University of Michigan, 1981.

10. M. Takeshita, H. Takahashi, and T. Okuda, Chem. Pharm. Bull., 10, 304 (1962).

11. S. Nigam and H. Y. Wang, ACS Symp., 314, 153 (1986).

12. A. -L. Nguyen and J.H. T. Luoung, Biotechnol. Bioeng., 28, 1261 (1986).

13. W. L. Muth and C. H. Nash, Antimicrob. Agents Chemotherap., 8, 321 (1975)

14. L. Sankaran and B. M. Pogell, Antimicrob. Agents Chemotherap., 8, 721 (1975)

15. J. Votruba and V. Běhal, Appl. Microbiol. Biotech., 19, 153 (1984). 